\title{
Article
}

\section{Knowledge of antimalarials and health seeking behaviour of households in case of suspected malaria in Democratic Repub- lic of the Congo}

\author{
Nsengi Y. Ntamabyaliro ${ }^{1 *}$, Christian Burri ${ }^{2,3}$, Yves N. Lula ${ }^{1}$, Daniel Ishoso ${ }^{4}$, Aline B. Engo ${ }^{1}$, Mireille A. Ngale ${ }^{1}$, \\ Jerry Y. Liwono ${ }^{1}$, Eric S. Mukomena ${ }^{6,7}$, Gauthier K. Mesia ${ }^{1}$, Samuel M. Mampunza ${ }^{1,5}$, Gaston L. Tona ${ }^{1}$. \\ 1. Unité de Pharmacologie Clinique, Faculté de Médecine, Université de Kinshasa, Kinshasa, Democratic Repu- \\ blic of the Congo. \\ 2. Swiss Tropical and Public Health Institute, Socinstrasse 57, 4002 Basel, Switzerland. \\ 3. University of Basel, Petersplatz 1, 4001 Basel, Switzerland \\ 4. École de Santé Publique, Faculté de Médecine, Université de Kinshasa, Kinshasa, Democratic Republic of \\ the Congo. \\ 5. Centre Neuropsychopathologique, Faculté de Médecine, Université de Kinshasa, Kinshasa, Democratic \\ Republic of the Congo. \\ 6. Programme National de Lutte Contre le Paludisme, Ministère de la Santé, Kinshasa, Democratic Republic of \\ the Congo. \\ 7. Faculté de Médecine, Université de Lubumbashi, Lubumbashi, Democratic Republic of the Congo \\ *Corresponding author: nsengi.ntama@unikin.ac.cd; Tel: +243815171991
}

\begin{abstract}
Background: The Democratic Republic of the Congo (DRC) is heavily affected by malaria despite availability of effective treatments. Ignorance and unrecommended behaviour toward a suspected malaria case in households may contribute to this problem. (2) Method: In communities of one rural and one urban Health Centers in each of the 11 previous provinces of DRC, all households with a case of malaria in the 15 days prior to the survey were selected. The patient or caregiver (responder) were interviewed. Logistic regression was used to assess predictors of knowledge of recommended antimalarials and good behaviour in case of suspected malaria. (3) Results: 1,732 households participated; about $62 \%$ (1060/1721) of the responders were informed about antimalarials, $70.1 \%(742 / 1059)$ knew the recommended antimalarial and 58.6\% (995/1699) resorted on selfmedication. Predictors of knowledge of antimalarials were education to secondary school or university, information from media and smaller households. Predictors of good behaviour were catholic religion and smaller households. Receiving information from CHW failed to be determinants of knowledge or adequate attitude. (4) Conclusion: malaria control in DRC is hampered by ignorance and non-adherence to national recommendations. These aspects are influenced by unsuccessful communication, size of households and level of education.
\end{abstract}

Keywords: Households; Antimalarial, health seeking behaviour, malaria, malaria treatment.

\section{Introduction}

Malaria is still causing a significant health burden in the Democratic Republic of the Congo (DRC) despite the implementation of numerous disease control tools including potent drugs. Over 40,000 people of the country's 90 million inhabitants, mainly children under five years old, still die from malaria per year. [1] Numerous parameters influence the effectiveness of drugs in everyday use. One of the under-researched factors negatively influencing effectiveness is the irrational use of drugs in health facilities and at community level. The World Health Organisation (WHO) estimates that children under-five, suffer from 6 to 10 malaria-related fever episodes per year[2], and similarly often from a fever of other origin.[3] Given an average household size of five to six members in the DRC, [4] 
and the incidence of malaria and other febrile illnesses, a health seeking decision with potentially fatal consequences has in average to be made every week.

The WHO and the National Malaria Control Program / Programme National de Lutte contre le Paludisme (PNLP) of the DRC recommend that each case of malaria confirmed by a malaria Rapid Diagnostic Test (mRDT) or microscopy shall be treated with recommended drugs as quickly as possible, latest within 24 hours. [5,6] Artemisinin-based combination therapies (ACT) are recommended in $\mathrm{DRC}[6]$ for their proven efficacy and safety.

Since malaria episodes start at the household, making correct early decisions is key: Children with signs of potential malaria infection should see the Community Health Worker (CHW) where available, or be presented to with no delay to a Health Centre. Instead, some patients or parents of sick children will resort to self-medication which is common in African and the DRC [7] [8] or revert to traditional or unconventional treatments depending on the information available in the household, the perceived urgency of the situation and economic considerations.

Understanding the knowledge, and the resulting behaviour of households in case of suspected malaria and their determinants will help to formulate better adapted and practicable strategies to guide patients and to reduce the number of fatalities in DRC.

\section{Materials and Methods}

Health area selection

At operation al level, the health system of the DRC is composed of 517 Health Zones (Zone de Santé), each of them served by at least one General Referral Hospital. Each Health zone is composed of several Health Areas (Aires de Santé) in which Health Centres (Centres de Santé) offer integrated health services for the local population. We carried out in 2014 a study on rational use of antimalarials in all the 11 provinces of the DRC. [9] DRC had not yet transitioned from 11 to 26 provinces at that time. In each province, one General Referral Hospital (GRH), one Rural Health Centre (RHC) and one Urban Health Centre (UHC) were selected for participation. The current study presented here, assessing the use of antimalarials at community level was carried out in the health areas of Rural and urban Health zones selected in the URAP study. GRH were not considered since their population is covered by the different Health centres of their Health Zone. The ensemble covers a catchment area of approximately 3 million inhabitants according to the data collected in health centres during the survey.

Household selection

All households in the selected regions having had a case of malaria, which presented to a participating health centre in the two weeks preceding the survey were selected. The addresses of these patients were extracted, and the listed households visited by the study teams.

Data collection

A questionnaire was developed, and pre-tested in 20 households in the Mont Amba Health Zone in Kinshasa. After this validation, the questionnaire was administered by investigators to the patient or caregiver of a sick child. Data were collected in March and April 2018. The following parameters were collected: Household size, age of the responder, education level of the responder, level of knowledge about antimalarials, and behaviour in case of a suspected malaria episode.

Assessment of knowledge about antimalarials was made in four steps: First, we sought to know if the responder had received information on malaria treatment; second, we asked the main source of this information; third, we asked if the drugs recommended for the management of malaria were known, and fourth, we verified this knowledge by asking to cite these drugs. If the responder was able to name at least one recommended antimalarial drug without mentioning a non-recommended drug, the answer classified the responder as knowing the antimalarials.

Behaviour was evaluated by asking what was normally done when malaria infection was suspected. Consulting the Community Health Worker, the Healthcare provider at the 
Health Centre or going to any health facility (public or private) for rapid Diagnostic Test (RDT) was considered as correct behaviour.

The data was entered using Epi-info 7, CDC Atlanta, then exported in Microsoft Excel 365 and analysed using Stata 14 software (StataCorp. 2015. Stata Statistical Software: Release 14. College Station, TX: StataCorp LP).

Statistical analysis

Variables were described by count or frequencies. When necessary, $\chi 2$ square test was used to compare them. A p value $<0.05$ was considered statistically significant. Logistic regression was used to assess determinants of the dependent variables, knowledge of antimalarials and good behaviour in case of suspected malaria. Age of the responder, sex, education level, location (urban or rural), religion, size of the household and source of information on antimalarials were considered as explanatory variables for knowledge of antimalarials. For good behaviour, the above-mentioned variables plus knowledge of the antimalarials were used as explanatory variables. After bivariate analyses, all variables with a statistical significance of 0.2 and below were included in the multivariate model. The final model was obtained by backward elimination.

Ethical consideration

This study did not expose participants to more than minimal risk. Approval was obtained from the Ethics Committee of the Protestant University of Congo under number CEUP 0048. All responders provided written informed consent; parents or legal representatives provided informed consent for minor responders, Confidentiality of their information is maintained: source data are only accessible to study team and kept in locked area. The data analysed did not include individual identifiers.

\section{Results}

All households with one or more cases of malaria during the previous 15 days were offered the possibility to participate in the study. 1,732 households participated in the study.

\subsection{Characteristics of the households}

More than half of the responders (53.2\%) lived in rural area; the median age was 37 years (6-98 years). Households were composed of an average of 7.1 members (CI 6.9-7.2). Half of the households (829/1700) were composed of $6-10$ persons; $36.7 \%$ of them had less than 6 persons and $14.6 \%$ more than 10 persons. About 3.5\% (19/1668) of the responders were minors. Regarding education, $57.8 \%$ of the responders $(981 / 1,699)$ were educated up to the secondary school; $18.8 \%$ up to primary school, $16.5 \%$ to university and $6.4 \%$ were illiterate. In terms of religion $34.5 \%(573 / 1,663)$ of the responders were Protestants, 33.0\% were Catholic, 23.8\% Evangelical Christians, 5.3\% Muslims, 2.5\% Kimbanguists. Less than $1 \%$ were followers of African religions.

Most of the responders $(1,060 / 1,721=61.6 \%)$ had been informed about malaria treatment. The main source of that information was health care professionals of the Health Centres as shown in table 1 . The next source of information was Media (radio, or television), followed by Community Health Workers (CHW). Surprisingly, less than $1 \%$ received information from Pharmacies, schools, and Churches, which are very frequented places in DRC. Most of the households (58.6\%) used self-medication in case of suspected malaria; $37.9 \%$ went to the Health Facilities whereas $3 \%$ used herbal medicines. None of the responders reported seeking health services from Community Health Workers. 
Table 1: Characteristics of the households

\begin{tabular}{|c|c|c|}
\hline & $\mathbf{N}$ & Percentage \\
\hline \multicolumn{3}{|l|}{ Location of the responders $(n=1,554)$} \\
\hline Rural area & 826 & $53.2 \%$ \\
\hline Urban area & 728 & $46.8 \%$ \\
\hline \multicolumn{3}{|l|}{ Age of the responders $(n=1,668)$} \\
\hline$<18 \mathrm{y}$ & 59 & $3.5 \%$ \\
\hline $18-50 \mathrm{y}$ & 1,251 & $75.0 \%$ \\
\hline $51-64 y$ & 278 & $16.7 \%$ \\
\hline $65 y$ & 81 & $4.9 \%$ \\
\hline \multicolumn{3}{|l|}{ Gender of the responders $(n=1,700)$} \\
\hline $\mathrm{F}$ & 981 & $57.7 \%$ \\
\hline $\mathrm{M}$ & 719 & $42.3 \%$ \\
\hline \multicolumn{3}{|c|}{ Education level of the head responders $(n=1,699)$} \\
\hline Illiterate & 111 & $6.5 \%$ \\
\hline Primary & 318 & $18.7 \%$ \\
\hline Secondary school & 981 & $57.8 \%$ \\
\hline University & 286 & $16.9 \%$ \\
\hline \multicolumn{3}{|l|}{$\underline{\text { Religion of the responders }(n=1,662)}$} \\
\hline Protestant & 573 & $34.5 \%$ \\
\hline Catholic & 549 & $33.0 \%$ \\
\hline Evangelical Christian & 396 & $23.8 \%$ \\
\hline Kimbanguist & 42 & $2.5 \%$ \\
\hline Muslim & 88 & $5.3 \%$ \\
\hline African religion & 8 & $0.5 \%$ \\
\hline Atheist & 6 & $0.4 \%$ \\
\hline \multicolumn{3}{|l|}{ Size of the household $(n=1,700)$} \\
\hline$<6$ persons & 623 & $36.7 \%$ \\
\hline 6-10 persons & 829 & $48.8 \%$ \\
\hline$>10$ persons & 248 & $14.6 \%$ \\
\hline \multicolumn{3}{|c|}{ Informed about treatment of malaria $(n=1,721)$} \\
\hline No & 661 & $38.4 \%$ \\
\hline Yes & 1,060 & $61.6 \%$ \\
\hline \multicolumn{3}{|c|}{ Know recommended malaria drugs $(n=1,059)$} \\
\hline No & 317 & $29.9 \%$ \\
\hline Yes & 742 & $70.1 \%$ \\
\hline \multicolumn{3}{|c|}{ Source of information on malaria drugs $(n=1,057)$} \\
\hline Staff of the Health Centre & 496 & $46.9 \%$ \\
\hline Media & 311 & $29.4 \%$ \\
\hline Community Health Workers & 132 & $12.9 \%$ \\
\hline Relatives & 84 & $7.9 \%$ \\
\hline Pharmacy & 3 & $0.3 \%$ \\
\hline Other & 27 & $2.6 \%$ \\
\hline Training & 4 & $0.4 \%$ \\
\hline \multicolumn{3}{|c|}{ Attitude in case of suspected malaria $(n=1,699)$} \\
\hline Self-medication & 995 & $58.6 \%$ \\
\hline Consultation to Health facility & 643 & $37.8 \%$ \\
\hline Use of Herbal medicine & 51 & $3.0 \%$ \\
\hline Other & 9 & $0.5 \%$ \\
\hline RDT in pharmacy & 1 & $0.1 \%$ \\
\hline
\end{tabular}




\subsection{Knowledge of recommended antimalarials}

Nearly two third of the responders (61.6\%) had been informed about recommended antimalarials; among them, $70.1 \%(742 / 1059)$ were able to name correctly at least one antimalarial recommended in DRC.

Table 2: Proportion of responders with knowledge of recommended antimalarials policy

\begin{tabular}{|c|c|c|c|}
\hline & \multicolumn{2}{|c|}{$\begin{array}{l}\text { Know recommended } \\
\text { antimalarials }\end{array}$} & \multirow[t]{2}{*}{$P$ value } \\
\hline & $\mathbf{N}$ & Percentage & \\
\hline \multicolumn{4}{|l|}{ Location of the responder $(n=969)$} \\
\hline Rural area $(n=500)$ & 352 & $70.4 \%$ & $\mathrm{P}=0.605$ \\
\hline Urban area $(n=469)$ & 323 & $68.9 \%$ & \\
\hline \multicolumn{4}{|c|}{ Education of the responders/head of household $(n=1,037)$} \\
\hline Illiterate $(\mathrm{n}=34)$ & 17 & $50.0 \%$ & $\mathrm{P}=0.010$ \\
\hline Primary school (n=164) & 104 & $63.4 \%$ & \\
\hline Secondary school (n=638) & 454 & $71.2 \%$ & \\
\hline University (n=201) & 148 & $73.6 \%$ & \\
\hline \multicolumn{4}{|c|}{ Age of the responders/head of household $(n=1,032)$} \\
\hline$\leqslant 18$ yo $(\mathrm{n}=31)$ & 24 & $77.4 \%$ & $P=0.639$ \\
\hline $18-<50$ y $(n=800)$ & 567 & $70.9 \%$ & \\
\hline $50-<65$ y $(n=161)$ & 109 & $67.7 \%$ & \\
\hline$\geqslant 65$ y $(n=40)$ & 29 & $72.5 \%$ & \\
\hline \multicolumn{4}{|c|}{ Gender of the responders/head of household $(n=1,040)$} \\
\hline Female $(\mathrm{n}=602)$ & 414 & $68.8 \%$ & $\mathrm{P}=0.487$ \\
\hline Male $(n=438)$ & 310 & $70.8 \%$ & \\
\hline \multicolumn{4}{|l|}{ Size of the household $(n=1,042)$} \\
\hline$<6$ persons $(\mathrm{n}=378)$ & 277 & $73.3 \%$ & $P=0.126$ \\
\hline $6-10$ persons $(n=507)$ & 349 & $68.8 \%$ & \\
\hline$>10$ persons $(n=157)$ & 102 & $65.0 \%$ & \\
\hline \multicolumn{4}{|l|}{ Informed about antimalarials $(n=1,055)$} \\
\hline No $(n=134)$ & 94 & $70.1 \%$ & $\mathrm{P}=0.978$ \\
\hline Yes $(n=921)$ & 645 & $70.0 \%$ & \\
\hline \multicolumn{4}{|l|}{$\underline{\text { Religion }(n=1,017)}$} \\
\hline Protestant $(n=316)$ & 227 & $71.8 \%$ & $\mathrm{P}=0.215$ \\
\hline Catholic $(n=370)$ & 269 & $72.7 \%$ & \\
\hline Evangelical Christian $(\mathrm{n}=231)$ & 148 & $64.1 \%$ & \\
\hline Kimbanguism $(\mathrm{n}=32)$ & 24 & $75.0 \%$ & \\
\hline Islam $(n=61)$ & 41 & $67.2 \%$ & \\
\hline African religions $(\mathrm{n}=4)$ & 2 & $50.0 \%$ & \\
\hline Atheist $(n=3)$ & 3 & $100.0 \%$ & \\
\hline \multicolumn{4}{|l|}{ Source of information $(n=916)$} \\
\hline Healthcare professionals $(\mathrm{n}=445)$ & 304 & $68.3 \%$ & $P=0.067$ \\
\hline Media $(n=255)$ & 195 & $76.5 \%$ & \\
\hline $\mathrm{CHW}(\mathrm{n}=122)$ & 78 & $63.9 \%$ & \\
\hline Relatives $(\mathrm{n}=65)$ & 40 & $61.5 \%$ & \\
\hline Pharmacy $(\mathrm{n}=3)$ & 2 & $66.7 \%$ & \\
\hline Other $(n=22)$ & 16 & $72.7 \%$ & \\
\hline Training $(\mathrm{n}=4)$ & 4 & $100.0 \%$ & \\
\hline
\end{tabular}


As shown in table 3, University and secondary school responders were more likely to know recommended antimalarials compared to illiterate $(\mathrm{OR}=2.50$ [1.04-6.00], $\mathrm{p}=0.040$, for university and 2.27 [1.00-5.15], $\mathrm{p}=0.049$ for secondary school). Responders from larger households were less likely to know recommended antimalarials; especially those from households with more than 10 persons $(\mathrm{OR}=0.63$ [0.41 - 0.98], $\mathrm{p}=0.039)$. Having received information on recommended antimalarials was not a determinant of their knowledge. However, one source of information is notably effective: The media (radio and television). Those who received information from Media were more likely to know recommended antimalarials compared to those who received information from medical staff of the Health Centres: $\mathrm{OR}=1.46$ [1.01 - 2.10], $\mathrm{p}=0.042$.

Table 3: Determinants of knowledge of recommended antimalarials

\begin{tabular}{ccccccc}
\hline \multicolumn{3}{l}{ Bivariate regression } & \multicolumn{3}{c}{ Multivariate regression } \\
\hline OR & $95 \%$ CI & P & aOR & $95 \%$ CI & P
\end{tabular}

Age of the responder

$\begin{array}{llll}6-18 \text { y } & 1 & & \\ 18-49 y & 0.71 & 0.30-1.67 & 0.432 \\ 50-64 \text { y } & 0.61 & 0.247-1.51 & 0.286 \\ \geq 65 \text { yо } & 0.77 & 0.26-2.29 & 0.637\end{array}$

\section{Gender of the responder}

F

$\mathrm{M}$
1

$1.09 \quad 0.84-1.44 \quad 0.488$

\section{Education of the responder}

Illiterate

Primary school

Secondary school 1

University

1.73

$0.82-3.65$

0.147

1

$2.47 \quad 1.23-4.93$

0.011

1.69

$.71-4.03$

0.236

2.79

$1.33-5.86$

0.007

2.27

$1.00-5.15$

0.049

Religion of the responder

Protestant

1

Catholic

1.04

$0.75-1.46$

0.800

Evangelical Christian

0.69

$0.48-1.00$

0.054

Kimbanguist

1.17

$0.51-2.71$

0.704

Muslim

0.80

$0.45-1.44$

0.467

African religion

0.39

$0.05-2.82$

0.353

Size of the household

$\begin{array}{llll}<6 \text { members } & 1 & & \\ \text { 6-10 members } & 0.80 & 0.59-1.08 & 0.151 \\ \geq 10 \text { members } & 0.68 & 0.45-1.00 & 0.055 \\ \text { No } & 1 & & \\ \text { Yes } & 0.99 & 0.67-1.48 & 0.978\end{array}$

Main source of information on antimalarials

Medical staff

Media

\section{1}

1.51

$1.06-2.14$

0.022

1

$1.46 \quad 1.01-2.10$

0.042 


\begin{tabular}{lllllll}
\hline CHW & 0.822 & $0.54-1.25$ & 0.361 & 0.84 & $0.55-1.30$ & 0.444 \\
Relatives & 0.74 & $0.43-1.27$ & 0.277 & 0.81 & $0.47-1.42$ & 0.470 \\
Pharmacy & 0.93 & $0.08-10.31$ & 0.951 & 0.93 & $0.08-10.41$ & 0.953 \\
Other & 1.24 & $0.47-3.23$ & 0.664 & 1.28 & $0.48-3.35$ & 0.622 \\
\hline
\end{tabular}

\subsection{Behaviour in case of suspected malaria}

In case of a suspected malaria, most of the responders (58.6\%) used self-medication; $37.8 \%$ went to the health facility for treatment and 3.0\% used herbal medicines. As shown in table 4 , the proportion of responders with recommended behaviour is greater in those educated for more than 6 years (secondary and University), those who knew recommended antimalarials and those who got information from media. In terms of religion, more Catholics and Kimbaguist adopt the recommended behaviour. In multivariate regression however, the predictor of good behaviour are religion of the responder and size of the household. Catholics are more likely to adopt recommended behaviour compared to Protestant $(\mathrm{aOR}=1.56$ [1.09-2.25], $\mathrm{p}=0.016)$ and responders from larger households ( $>10$ persons) are less likely to adopt recommended behaviour ( $\mathrm{aOR}=0.60$ [0.37-0.98], $\mathrm{p}=0.042$ ). There is a possible impact of education and knowledge of antimalarial as differences are almost statistically significant: knowing antimalarials could increase by $37 \%$ the likelihood of good attitude $(p=0.067$ ). In terms of education, University responders behave comparably to illiterate while primary and secondary school responders seem to be less likely to adopt recommended attitude compared to illiterate, but differences are not statistically significant as shown in table 5. Source of information on antimalarial is not a predictor of recommended behaviour.

Table 4: Proportion of responders with recommended behaviour in case of suspected malaria

\begin{tabular}{|c|c|c|c|}
\hline \multirow[t]{2}{*}{ Variable } & \multicolumn{2}{|c|}{ Recommended behaviour } & \multirow[t]{2}{*}{ P value } \\
\hline & $\mathbf{N}$ & Percentage & \\
\hline \multicolumn{4}{|c|}{ Education of the responders $(n=1,666)$} \\
\hline Illiterate $(n=110)$ & 34 & $30.9 \%$ & $\mathrm{P}=0,001$ \\
\hline Primary school $(n=312)$ & 95 & $30.4 \%$ & \\
\hline Secondary school $(n=963)$ & 368 & $38.2 \%$ & \\
\hline University $(\mathrm{n}=\mathbf{2 8 1})$ & 129 & $45.9 \%$ & \\
\hline \multicolumn{4}{|l|}{ Age of the responders $(n=1,636)$} \\
\hline$\leqslant 18$ yo $(n=58)$ & 21 & $36.2 \%$ & $\mathrm{P}=0.523$ \\
\hline $18-<50$ y $(n=1,228)$ & 452 & $36.8 \%$ & \\
\hline $50-<65$ y $(n=271)$ & 107 & $39.5 \%$ & \\
\hline$\geqslant 65$ y $(n=79)$ & 29 & $36.7 \%$ & \\
\hline \multicolumn{4}{|c|}{ Gender of the responders $(n=1,671)$} \\
\hline Female $(n=966)$ & 353 & $36.5 \%$ & $\mathrm{P}=0.229$ \\
\hline Male $(n=705)$ & 278 & $39.4 \%$ & \\
\hline \multicolumn{4}{|l|}{ Size of the household $(n=1,671)$} \\
\hline$<6$ persons $(n=614)$ & 239 & $38.9 \%$ & $\mathrm{P}=0.559$ \\
\hline $6-10$ persons $(n=814)$ & 310 & $38.1 \%$ & \\
\hline$>10$ persons $(n=243)$ & 85 & $35.0 \%$ & \\
\hline \multicolumn{4}{|c|}{ Informed about antimalarials $(n=1,690)$} \\
\hline No $(n=644)$ & 238 & $36.9 \%$ & $\mathrm{P}=0,544$ \\
\hline Yes $(n=1046)$ & 402 & $38.4 \%$ & \\
\hline Know antimalarials $(n=1,046)$ & & & \\
\hline
\end{tabular}




\begin{tabular}{|c|c|c|c|}
\hline No $(n=315)$ & 96 & $30.5 \%$ & $\mathrm{P}=0,001$ \\
\hline Yes $(n=731)$ & 299 & $40.9 \%$ & \\
\hline \multicolumn{4}{|c|}{ Religion of the responders $(n=1,632)$} \\
\hline Protestant $(n=562)$ & 211 & $37.5 \%$ & $\mathrm{P}=0.065$ \\
\hline Catholic $(n=540)$ & 220 & $40.7 \%$ & \\
\hline Bible Christian $(n=386)$ & 132 & $33.9 \%$ & \\
\hline Kimbanguism (n=42) & 23 & $54.8 \%$ & \\
\hline Islam $(\mathrm{n}=88)$ & 26 & $29.5 \%$ & \\
\hline African religions $(n=8)$ & 4 & $50.0 \%$ & \\
\hline Atheist $(n=6)$ & 3 & $50.0 \%$ & \\
\hline \multicolumn{4}{|l|}{ Source of information $(n=1,045)$} \\
\hline HF staff $(n=490)$ & 191 & $39.0 \%$ & 0.269 \\
\hline Media $(n=307)$ & 127 & $41.4 \%$ & \\
\hline CHW $(n=131)$ & 42 & $32.1 \%$ & \\
\hline Relatives $(n=83)$ & 27 & $32.5 \%$ & \\
\hline Pharmacy $(n=3)$ & 1 & $33.3 \%$ & \\
\hline Other $(n=27)$ & 12 & $44.4 \%$ & \\
\hline Training $(n=4)$ & 0 & $0.0 \%$ & \\
\hline
\end{tabular}

Table 5: Determinants of recommended behaviour

\begin{tabular}{|c|c|c|c|c|c|c|}
\hline & OR & $95 \% \mathrm{CI}$ & $\mathrm{P}$ & $\mathrm{aOR}$ & $95 \% \mathrm{CI}$ & $\mathrm{P}$ \\
\hline \multicolumn{7}{|l|}{ Age of the responder } \\
\hline $6-18$ yo & 1 & & & & & \\
\hline $18-49$ yo & 1.03 & $0.59-1.78$ & 0.926 & & & \\
\hline $50-64$ yo & 1.15 & $0.64-2.07$ & 0.642 & & & \\
\hline $65 y o$ and above & 1.02 & $0.50-2.07$ & 0.952 & & & \\
\hline \multicolumn{7}{|l|}{ Gender of the responder } \\
\hline $\mathrm{F}$ & 1 & & & & & \\
\hline M & 1.13 & $0.93-1.38$ & 0.229 & & & \\
\hline \multicolumn{7}{|l|}{ Education of the responder } \\
\hline Illiterate & 1 & & & & & \\
\hline Primary school & 0.98 & $0.61-1.57$ & 0.928 & 0.37 & $0.13-1.04$ & 0.059 \\
\hline Secondary school & 1.38 & $0.90-2.11$ & 0.135 & 0.58 & $0.22-1.52$ & 0.27 \\
\hline University & 1.90 & $1.19-3.03$ & 0.007 & 1.03 & $0.38-2.83$ & 0.95 \\
\hline \multicolumn{7}{|l|}{ Religion of the responder } \\
\hline Protestant & 1 & & & & & \\
\hline Catholic & 1.14 & $0.90-1.46$ & 0.277 & 1.56 & $1.09-2.25$ & 0.016 \\
\hline Evangelical Christian & 0.86 & $0.66-1.13$ & 0.292 & 0.80 & $0.51-1.24$ & 0.313 \\
\hline Kimbanguist & 2.01 & $1.07-3.78$ & 0.030 & 2.12 & $0.92-4.89$ & 0.077 \\
\hline Muslim & 0.70 & $0.43-1.14$ & 0.149 & 0.76 & $0.37-1.53$ & 0.438 \\
\hline African religion & 1.66 & $0.41-6.72$ & 0.475 & 10.50 & $0.88-125.11$ & 0.063 \\
\hline Atheist & 1.66 & $0.33-8.32$ & 0.535 & 0.61 & $0.05-7.68$ & 0.703 \\
\hline
\end{tabular}


Size of the household

$\begin{array}{lllllll}<6 \text { members } & 1 & & & & & \\ \text { 6-10 members } & 0.97 & 0.78-1.20 & 0.746 & 0.81 & 0.58-1.12 & 0.204 \\ \geq 10 \text { members } & 0.84 & 0.62-1.15 & 0.283 & 0.60 & 0.37-0.98 & \mathbf{0 . 0 4 2}\end{array}$

$\underline{\text { Informed about antimalarials }}$

No 1

Yes 1.06

$\begin{array}{lll}1.06 & 0.87-1.30 & 0.544\end{array}$

$\underline{\text { Know antimalarials }}$

No 1

Yes 1.58

1.58

$1.19-2.09$

0.001

$1.37 \quad 0.98-1.92$

0.067

$\underline{\text { Source of information on antimalarials }}$

\begin{tabular}{lllllll} 
Medical staff & 1 & & & & & \\
Media & 1.10 & $0.83-1.48$ & 0.503 & 1.19 & $0.84-1.71$ & 0.33 \\
CHW & 0.74 & $0.49-1.11$ & 0.147 & 0.69 & $0.42-1.14$ & 0.148 \\
Relatives & 0.75 & $0.46-1.24$ & 0.264 & 0.67 & $0.35-1.28$ & 0.223 \\
Pharmacy & 0.78 & $0.07-8.69$ & 0.842 & 1.02 & $0.09-12.25$ & 0.985 \\
Other & 1.25 & $0.57-2.73$ & 0.572 & 1.25 & $0.46-3.40$ & 0.66 \\
\hline
\end{tabular}

\section{Discussion}

This study focused on households in the communities served by the health centres described our previous study.[9] We investigated the determinants of knowledge of antimalarials and behaviour towards a suspected malaria case.

A total of $63.4 \%$ of the households were composed of more than 6 persons and the average size of household was 7.1 persons. This is greater than the average household size in DRC (5.3 persons) according to the last Health and Demographic Surveillance (HDS). [4] The larger household size in our study may be due to targeting households with malaria cases. In facts, some studies, including in DRC, have shown that larger households are at increased risk of malaria.[10-12]; this may have resulted in overrepresentation of larger households in our sample. Most importantly, size of the households should be taken in account in the malaria control activities because, being part of a large household ( $>10$ people) significantly decreased the likelihood of knowing the recommended antimalarials and adopting recommended behaviour. Larger families are also more likely to resort to self-medication. [28] A study in the DRC showed that self-medication mostly concerns antimalarials, and that the users usually do not know the exact dosage of the drug used and do not check the expiry date. [8] Drugs used in self-medication come from Pharmacies, non-official drug sellers and sometimes leftover of pervious malaria and neighbours. [13] This may result in harmful outcomes and needs to be addressed.[14] Since larger households are, at the same time, at increased risk for malaria, [4-6] and, prone to ignorance and unrecommended behaviour, special attention needs to be paid to them and ways must be found to help them get involved in the fight against Malaria. CHW and other health workers could target these families and support them in the fight against malaria. This assumes the capacitation of these agents to improve their performance.

$61.6 \%$ of the responders $(1,060 / 1,721)$ had been informed about recommended antimalarial treatment and, $70.7 \%(742 / 1,059)$ were able to name at least one recommended antimalarial. Since we are talking of a disease that kills more than 40,000 of people, mostly children every year in the country;[1] measures should be put in place to ensure better knowledge of the recommended drugs. It is important to use the most effective ways to 
communicate that information to the population and to make sure the information is suitable for the audience: Having information on antimalarial failed to be a predictor of their knowledge. However, knowledge of antimalarials was better when the responder was more educated, came from a smaller household, and had received information from the media. Multivariate regression shows that university or high school education is a statistically significant predictor of better knowledge of antimalarials. Primary school is not a predictor of knowledge and may reduce the likelihood of adopting recommended attitude. This is in line with a study in Nigeria that found completion of only basic education to be associated with a reduction in the likelihood of seeking healthcare from formal sources.[15] A higher level of education indeed allows a better understanding of the message provided, not only by the medical staff of the HC which is the most prevalent source of information, but also from the media and other source of information. However, not all population is highly educated. In our study, $6.6 \%$ of the responders were illiterate and $18.9 \%$ had only basic education in primary school. Since this population is likely to be concerned by malaria, messages adapted to them should also be provided. Such adaptation should include, not only the information tools (image boxes), but also the language used. In the context of the DRC with French as the official and teaching language, while the national languages (Lingala, Swahili, Kikongo, or Tshiluba) are used for daily communication, language is crucial: Medical Doctors and all medical staff are educated for years in French and because of this, they tend to use it for daily communication including with patients. This may create a language barrier that may explain why the principal source of information for almost half of the respondents (medical staff of the HC) fails to be the best determinant of knowledge of malaria drugs. Indeed, there may be language barriers in communication between medical staff and patients $[16,17]$, especially those from villages, in poor countries [18] like DRC.

The second and the best source of information on antimalarials is mass media, especially radio and television. This source is a significant predictor of best knowledge of antimalarials. Indeed, mass media play an important role in healthcare communication in the $21^{\text {st }}$ Century; $[19,20]$ They reach many persons at a time. Moreover, the language is simpler, associated with images and performances of famous comedians, musicians, film actors and other celebrities. This catches attention and facilitate comprehension of the message. Since the media are an important and more effective source of information on malaria treatment, they should be used more, and the message conveyed should be diversified. Social media which are increasingly taking up space alongside traditional media [21] should also be used and could produce results comparable if not superior to traditional media.

There is also a need to communicate malaria information in churches and other religious meeting places. The fact that only 2 persons received the information from the churches suggests that the information on malaria is not sufficiently conveyed in these places. Since the population of the DRC is known to be deeply religious [22] and because religion has an influence on households practice regarding malaria [23], churches would be a good place to spread messages about antimalarials. In addition, religion had an influence on the behaviour of our responders. For example, belonging to evangelical churches in which miracle healing is one of the main teachings, may decrease by $20 \%$ the likelihood of adopting the recommended behaviour in case of suspected malaria, but the decrease was not statistically significant. On the other hand, Catholic religion, which teaches less about miracle healing, is a statistically significant predictor of recommended attitudes; the same has been shown in another study in Nigeria. [24] Nevertheless, giving message on malaria and its treatment in churches could be a way to reach a great number of Congolese and help them know better for better behaviour.

Another source of information that needs attention is community health workers (CHW): They are the third source of information for families and their importance has been described in several studies. They are considered as the backbone of the elimination of malaria; [25] their involvement in integrated Community Management of Malaria 
(iCCM) has produced positive results in terms of early and appropriate treatment of Malaria. [26] Since CHWs typically reside in the community they serve; they have the unique ability to bring information where it is needed most. They can reach community residents where they live, eat, play, work, and worship. [27] Hence, CHWs can be crucial for adequate health seeking behaviour, and they are predestined to give advice on treatment adherence and about the risks of self-treatment. However, none of the responders reported seeking health services from $\mathrm{CHW}$ in case of suspected malaria. CHW are supposed to provide healthcare services concerning malaria, acute respiratory infections, and diarrhea to populations in the most remote areas, but our responders did not mention using their services. This could mean insufficient communication about the services provided by community health workers or proximity of our responders to other health facilities. CHW are present and active in the selected communities since they are mentioned as the third source of information on antimalarials, but their intervention does not seem to be effective or noted as relevant. The likelihood of knowing antimalarials and adopting recommended behaviour, was found to be diminished by $20 \%$ and $30 \%$, respectively, when the information came from the $\mathrm{CHW}$ compared to medical staff of the HC. The decrease is not statistically significant, but this may mean that there need to be a reflection on the role of $\mathrm{CHW}$ in communication of information on malaria treatment and their education. Another study in the DRC showed their importance in reducing the prevalence of malaria in a rural area, but nevertheless saw the difficulty of perpetuating their activity. [28] CHW usually come from low socio-economic background, [29] and most of them work on a voluntary basis. [27,29] Adequate training and appropriate motivation and incentives may improve their performances. This may include provision of uniforms or badges for identification, bicycles or funding for transport, formal job descriptions and performance evaluation tools. [30]

In summary, it is of paramount importance to improve knowledge of antimalarial drugs in the population. Other studies have shown that knowledge of malaria to be a determinant of health seeking behaviour, [31-33] but in our study, statistical signification was not attained $(\mathrm{p}=0.067)$. However, it is important to note that knowledge of antimalarials could increase by $37 \%$ the probability of adopting the recommended behaviour towards a Malaria case.

\section{Conclusions}

DRC has the second highest morbidity and mortality rates related to malaria worldwide. The level of knowledge and attitude of the communities towards malaria cases, suggest that DRC is set to be losing out: The level of knowledge among communities is too low for a disease as widespread and deadly as malaria. In addition, most of the households do not adopt the recommended behaviour towards a suspected malaria case. There is a need for more effective communication, and this includes empowering CHW, adaptation of the message provided by medical staff and usage of more effective ways like media, social media, and churches. Considering the high attendance of churches in DRC, communication about malaria in this place may be highly efficient. Special attention is needed for larger families, which are more affected by malaria and more prone to nonrecommended attitudes. An emphasis on education, not simply basic but at least at the secondary level is necessary to better understand information about malaria and behave better. This enforces the mandatory multisectoral nature of the fight against malaria, which should include socioeconomic aspects and education.

Author Contributions: “Conceptualization, N.Y.N, E.S.M and G.L.T; methodology, N.Y.N and Y.N.L.; validation, N.Y.N. and A.B.E; formal analysis, N.Y.N and D.I..; resources, E.S.M and G.L.T.; data curation, N.Y.N and Y.N.L. ; writing-original draft preparation, N.Y.N.; writing-review and editing, C.B., Y.N.L, D.I., A.B.E., M.A.N., J.Y.L., E.S.M., G.K.M., S.M.M., and G.L.T..; supervision, G.L.T. and S.M.M. All authors have read and agreed to the published version of the manuscript.". 
Funding: This research was funded by the Global Fund to Fight AIDS, Tuberculosis and Malaria, grant number NMF1

Institutional Review Board Statement: The study was conducted according to the guidelines of the Declaration of Helsinki and approved by the Institutional Review Board of PROTESTANT UNIVERSITY OF KINSHASA under number CEUP 0048E on 07 March 2018.

Informed Consent Statement: Informed consent was obtained from all subjects involved in the study; parents or legal representatives provided informed consent for minor responders.

Data Availability Statement: All excel files are available from the Figshare database DOI:

10.6084/m9.figshare.14046101

Acknowledgments: Funding of this study was provided by the Global Fund to fight AIDS, Tuberculosis and Malaria. We thank National Malaria Control Programme of DRC (Programme National de Lutte contre le Paludisme) and all the site supervisors for support and assistance: Bodjick Muena Mujobu Trésor, Divengi Nzambi Jean-Paul, Kondani Apeangangn Mamy, Lusakibanza Manzo Mariao, Makila Bool Félicité, Mbo Modiri Clarisse, Mboma Mapipi Odette, Miti Mbemba Hendrick, Mpiempie Ngmasate Thérèse, Mvete Luemba Bibiche, Mwanga Malewu André, Ngoy Kankieza Francis, Nsibu Ndosimao Célestin, Nseka Zi Nseka Arnold, Nsimba Mbangi Gancia, Pandi belebinda David, Sarah Hailemariam Nehema, and Songo Milete Georgette.

Conflicts of Interest: The authors declare no conflict of interest.

\section{References}

1. Global Malaria Programme: WHO Global. World malaria report 2019 [Internet]. WHO Reg. Off. Africa. 2019. Available from: https://www.who.int/news-room/fact-sheets/detail/malaria

2. WHO. Health Action in Crises 1 DEMOCRATIC REPUBLIC OF THE CONGO (DRC) THE PRESENT CONTEXT. 2007.

3. D'Acremont V, Kilowoko M, Kyungu E, Philipina S, Sangu W, Kahama-Maro J, et al. Beyond malaria - Causes of fever in outpatient Tanzanian children. N Engl J Med. 2014;370:809-17.

4. Ministère de la Santé Publique, Modernité M du P et S de la M en œuvre de la R de la. Enquête Démographique et de Santé en République Démocratique du Congo 2013-2014. 2014;44:957-60.

5. WHO. Guidelines for the treatment of malaria third edition. 2015.

6. Programme National de Lutte contre le Paludisme. Guide National de Prise en charge du Paludisme. 2012;

7. Mwita S, Meja O, Katabalo D, Richard C. Magnitude and factors associated with anti-malarial self-medication practice among residents of Kasulu Town Council, Kigoma-Tanzania. Afr Health Sci. 2019;19:2457-61.

8. Katumbo AM, Tshiningi TS, Sinanduku S, Mudisu LK, Mulunda P, Mukuku O, et al. The practice of self-medication in children by their mothers in Lubumbashi, Democratic Republic of Congo. 2020;27-31.

9. Ntamabyaliro NY, Burri C, Nzolo DB, Engo AB, Lula YN, Mampunza SM, et al. Drug use in the management of uncomplicated malaria in public health facilities in the Democratic Republic of the Congo. Malar J. 2018;17.

10. Ngatu NR, Kanbara S, Renzaho A, Wumba R, Mbelambela EP, Muchanga SMJ, et al. Environmental and sociodemographic factors associated with household malaria burden in the Congo. Malar J [Internet]. BioMed Central; 2019;18:1-9. Available from: https://doi.org/10.1186/s12936-019-2679-0

11. Kaindoa EW, Mkandawile G, Ligamba G, Kelly-Hope LA, Okumu FO. Correlations between household occupancy and malaria vector biting risk in rural Tanzanian villages: Implications for high-resolution spatial targeting of control interventions. Malar J. BioMed Central; 2016;15:1-12.

12. Shcherbacheva A, Haario $H$. The impact of household size on malaria reduction in relation with alterations in mosquito behavior by malaria parasite. J Mult Log Soft Comput. 2017;29:455-68.

13. Kimoloi S, Nicky O, Ondigo BM, Langat BK. Choice and sources of antimalarial drugs used for self-medication in Kisumu, 
Western Kenya. Afr J Pharm Ther. 2013;2:124-9.

14. Sciences H, Henrietta IN, Olusola IA, Bayonle AU, Aminat OB, Kingsley I. World Journal of Biology Pharmacy and Health Sciences. 2020;02:19-29.

15. Latunji OO, Akinyemi OO, Health F. FACTORS INFLUENCING HEALTH-SEEKING BEHAVIOUR AMONG CIVIL SERVANTS IN IBADAN , NIGERIA. 2018;16.

16. Green AR. The Impact of Language Barriers on Health Care. Solutions. 2007;

17. Al Shamsi H, Almutairi AG, Al Mashrafi S, Al Kalbani T. Implications of Language Barriers for Healthcare: A Systematic Review. Oman Med J. 2020;35:e122-e122.

18. Language Barriers In The Medical Field Can Cause a Big Problem [Internet]. [cited 2020 Aug 6]. Available from: https://www.daytranslations.com/blog/language-barriers-medical-field/

19. Naveena N. Importance of Mass Media in Communicating Health Messages: An Analysis. IOSR J Humanit Soc Sci [Internet]. 2015;20:36-41. Available from: www.iosrjournals.org

20. Future T, Committee C, Isbn C, Pdf T, Press NA, Press NA, et al. THE FUTURE OF THE PUBLIC'S HEALTH in the 21st Century Library of Congress Cataloging-in-Publication Data [Internet]. 2002. Available from: http://www.nap.edu/catalog/10548.html

21. Anand S, Gupta M, Kwatra S. Social Media and Effective Health Communication. Int J Soc Sci Interdiscip Res. 2013;2:39-46.

22. Congo, Democratic Republic of the, Religion And Social Profile I National Profiles I International Data I TheARDA [Internet]. [cited 2020 Aug 22]. Available from: http://www.thearda.com/internationalData/countries/Country_57_1.asp

23. Yahaya Maigemu A, Bt Haji Hassan K. Influence of Religion on Malaria Control Practices among Household Heads in Zamfara State North West Nigeria. J Cult Soc Dev [Internet]. 2015;10:78-84. Available from: www.iiste.org

24. Ihaji E, Gerald EU, Helen C, Ogwuche E. Educational Level, Sex and Church Affiliation on Health Seeking Behaviour among Parishioners in Makurdi Metropolis of Benue State. 2014;1:311-6.

25. Community health workers: The backbone of malaria elimination I PATH [Internet]. [cited 2020 Jun 28]. Available from: https://www.path.org/articles/community-health-workers-malaria-elimination/

26. WHO I Integrated community case management of malaria. WHO [Internet]. World Health Organization; 2017 [cited 2020 Jul 14]; Available from: http://www.who.int/malaria/areas/community_case_management/overview/en/

27. Role of Community Health Workers, NHLBI, NIH [Internet]. [cited 2021 Feb 2]. Available from: https://www.nhlbi.nih.gov/health/educational/healthdisp/role-of-community-health-workers.htm

28. Delacollette C, Van Der Stuyft P, Molima K. Using community health workers for malaria control: Experience in Zaire. Bull World Health Organ. 1996;74:423-30.

29. Ormel H, Kok M, Kane S, Ahmed R, Chikaphupha K, Rashid SF, et al. Salaried and voluntary community health workers: Exploring how incentives and expectation gaps influence motivation. Hum Resour Health. Human Resources for Health; 2019;17:1-12.

30. Kerry Millingto. Effectiveness of Community Health Workers. A Syst Rev. 2018;9-12.

31. Mitiku I, Assefa A. Caregivers' perception of malaria and treatment-seeking behaviour for under five children in Mandura District, West Ethiopia: A cross-sectional study. Malar J. BioMed Central; 2017;16:1-10.

32. Workineh B, Mekonnen FA. Early treatment-seeking behaviour for malaria in febrile patients in northwest Ethiopia 11 Medical and Health Sciences 1117 Public Health and Health Services. Malar J [Internet]. BioMed Central; 2018;17:1-8. Available from: https://doi.org/10.1186/s12936-018-2556-2 
33. Chinweuba AU, Agbapuonwu NE, Onyiapat JLE, Israel CE, Ilo CI, Arinze JC. Determinants of Malaria Prevention and Treatment Seeking Behaviours of Pregnant Undergraduates Resident in University Hostels, South-East Nigeria. J Pregnancy. 2017;2017. 